\title{
Study of the Prevalance of Congenital Uterine Anomalies during Cesarean Section
}

Rekha $\mathrm{N}^{1}$, Roopa N. K ${ }^{2 *}$

${ }^{1}$ Professor Department of Obstetrics and Gynecology, BGS Global institute of medical sciences Bangalore, Karnataka, India

${ }^{2}$ Associate professor Department of Obstetrics and Gynecology, BGS Global institute of medical sciences Bangalore, Karnataka, India

DOI: $10.36347 /$ sasjm.2020.v06i12.004

| Received: 29.11.2020 | Accepted: 14.12.2020 | Published: 16.12.2020

*Corresponding author: Roopa N. K

Abstract

Original Research Article

Congenital uterine anomalies are a result of abnormal formation, fusion or resorption of Müllerian ducts during fetal life [1]. The actual prevalence of uterine anomalies in the general population is not known. Recent studies indicated that the prevalence of uterine anomalies varies from $0.1 \%$ to $10 \%$ in general population [2-4] and 5- 25\% in women with adverse pregnancy outcome. This study is conducted to determine the prevalence of congenital uterine anomalies discovered during Caesarean section. Methods: This is a Prospective observational study conducted in the Department of Obstetrics and Gynecology of BGSGIMS, Bangalore. All women who underwent Caesarean section during 2017 2019 (over a period of 2 years) were included in the study. After delivery of the fetus and placenta, digital exploration of the uterine cavity was done to identify uterine anomaly and fundus of uterus was examined after exteriorization. Uterine anomalies if discovered were noted. Results: During the study period of 2 years, 1560 Caesarean sections were performed. Out of 1560 women who underwent cesarean section, 31(1.98\%) women were diagnosed with uterine anomalies and 1529 (98\%)women had normal uterus. In the study population, of the $555(35.57 \%)$ primigravida who underwent Caesarean section, 20 (64.51\%) women were diagnosed with uterine anomalies and out of 1005 (64.42\%) multigravida $11(35.48 \%)$ women were diagnosed with uterine anomalies. 17 (54.8\%) out of 31 women diagnosed with uterine anomalies belonged to the age group of 25-30 years. In the study population most common uterine anomaly identified is bicornuate uterus (45.16\%) and next common is arcuate uterus $(32.25 \%)$.In the study group most women with uterine anomaly had breech presentation (77.41\%) and next common was vertex presentation (32.25\%). Conclusions: Prevalence of Congenital uterine anomalies in the study population is $1.98 \%$ and prevalence of uterine anomalies with abnormal presentation is $11 \%$.

Keywords: Congenital uterine anomaly, Abnormal Presentation, Caesarean Section, prevalence.

Copyright $(\odot 2020$ The Author(s): This is an open-access article distributed under the terms of the Creative Commons Attribution 4.0 International License (CC BY-NC 4.0) which permits unrestricted use, distribution, and reproduction in any medium for non-commercial use provided the original author and source are credited.

\section{INTRODUCTION}

A uterine malformation is a type of female genital malformation resulting from an abnormal formation, fusion or resorption of Müllerian ducts during fetal life [1]. These anomalies are often asymptomatic and unrecognized, but recent study indicated that the prevalence of uterine anomalies varies from $0.1 \%$ to $10 \%$ in general population [2-4] and 5$25 \%$ in women with adverse pregnancy outcome. Uterine abnormalities are not usually diagnosed at birth, even with the presence of an anomaly; the uterus may still function normally. Uterine anomalies are usually reported only when women present with adverse pregnancy outcomes or gynecologic symptoms.

Pitfalls in reporting could be due to wide range of incidence and prevalence rates because of no standardization of classification systems, no uniform diagnostic modalities, and different study populations of women are included [5].

The classification described by the American Society of Reproductive Medicine [AFS] [6] remains the most widely used where Uterine anomalies are classified as mullerian agenesis, unicornuate uterus, bicornuate uterus, Septate uterus, Arcuate uterus, didelphys, DES exposed uterus.

Prevalence of uterine anomalies depends on different diagnostic modality. Nahum reported bicornuate uterus as the most common uterine anomaly followed by septate uterus [7]. While Grimbizis et al., reported a higher prevalence for arcuate and septate uteri followed by bicornuate uteri [8]. 
Uterine anomalies are associated with adverse maternal outcomes like infertility, recurrent miscarriages, preterm birth, mal presentations and increased rate of Caesarean section.

Uterine anomalies can be diagnosed during cesarean section. By diagnosing the anomaly we can analyze adverse maternal outcome the women may have in future pregnancy, its impact on their future obstetric and gynecological management [9]. This study is conducted to determine the prevalence of congenital uterine anomalies discovered during Caesarean section.

\section{METHODS}

This was a prospective observational study conducted at the Department of Obstetrics and Gynecology of BGSGIMS hospital, Bangalore. All women who underwent cesarean section during 2017 to 2019 (2yrs) were included in the study. Total number of 1560 women was enrolled in the study. After delivery of the fetus and the placenta; uterus was examined for the presence or absence of congenital anomaly by digital palpation of the uterine cavity and uterine fundus examined after exteriorization.

Uterine septum was diagnosed if there was any degree of midline fleshy protrusion inside the uterine cavity on palpation. Bicornuate uterus was diagnosed if there was a depression in the uterine fundus with two separate uterine cavities by digital palpation. Unicornuate uterus was diagnosed if there was single uterine cavity and fallopian tube and opposite uterine wall will be flat with no fallopian tube and ovary; however rudimentary horn may or may not be visualized during cesarean section. Arcuate uterus was diagnosed if there was an indentation on the fundus of uterus and cavity was normal. Uterus didelphys was diagnosed when on examination we see double uterus, double cervix, septate vagina, the endometrial cavities widely separated and there is a profound indentation on the fundal contour. At the end of surgery, speculum examination was done and two separate cervices were revealed.

Table-1: Prevalence of uterine anomalies during cesarean section and frequency of uterine anomalies with mal presentation and Vertex presentation

\begin{tabular}{|l|l|l|l|}
\hline & TOTAL CASES & NORMAL UTERUS & ANOMALOUS UTERUS \\
\hline TOTAL NUMBER of LSCS (2yrs) PERCENTAGE & 1560 & $1529(98 \%)$ & $31(1.98 \%)$ \\
\hline LSCS - MALPRESENTATION & 180 & $159(88 \%)$ & $\mathbf{2 1}(11 \%)$ \\
\hline VERTEX PRESENTATION & 1380 & $1370(99.27 \%)$ & $10(0.72 \%)$ \\
\hline
\end{tabular}

Prevalence of uterine anomaly during cesarean section in our study is $1.98 \%$ which is significant.

Table-2: Maternal age distribution

\begin{tabular}{|l|l|l|l|}
\hline $\begin{array}{l}\text { MATERNAL AGE } \\
\text { in yrs }\end{array}$ & $\begin{array}{l}\text { TOTAL CASES } \\
1560\end{array}$ & $\begin{array}{l}\text { NORMAL UTERUS } \\
1529\end{array}$ & $\begin{array}{l}\text { ANOMALOUS UTERUS } \\
31\end{array}$ \\
\hline$<18$ & 0 & 0 & 0 \\
\hline $19-24$ & $235(15.06 \%)$ & $229(14.97 \%)$ & $6(19.35 \%)$ \\
\hline $25-30$ & $1087(69.67 \%)$ & $1070(69.98 \%)$ & $17(54.8 \%)$ \\
\hline $30-35$ & $201(12.88 \%)$ & $196(12.81 \%)$ & $5(16.12 \%)$ \\
\hline$>35$ & $37(2.37 \%)$ & $34(2.22 \%)$ & $3(9.6 \%)$ \\
\hline
\end{tabular}

Most of the uterine anomalies were detected in the age group of $25-30$ yrs.

Table-3: Distribution of parity in women with normal and anomalous uterus

\begin{tabular}{|l|l|l|l|}
\hline PARITY & TOTAL CASES 1560 & NORMAL UTERUS 1529 & ANOMALOUS UTERUS 31 \\
\hline PRIMI & 555 $(35.57 \%)$ & $535(34.9 \%)$ & $20(64.51 \%)$ \\
\hline MULTI & $1005(64.42 \%)$ & $994(65.0 \%)$ & $11(35.48 \%)$ \\
\hline
\end{tabular}

Primary section for anomalous uterus is almost twice $(64.51 \%)$ than for normal uterus. Secondary section most of the indications were previous cesarean section.

Table-4: Uterine anomalies in the study group

\begin{tabular}{|l|l|}
\hline UTERINE ANOMALIES & NUMBER OF WOMEN $(\mathbf{n}=31)$ \\
\hline Bicornuate & $14(45.16 \%)$ \\
\hline Unicornuate & $\mathbf{2 ( 6 . 4 6 \% )}$ \\
\hline Arcuate & $10(32.25 \%)$ \\
\hline Septate / Subseptate & $\mathbf{4}(12.90 \%)$ \\
\hline Didelphys & $1(3.22 \%)$ \\
\hline
\end{tabular}

In the study population most common uterine anomaly identified was bicornuate uterus (45.16\%), next common is arcuate uterus $(32.25 \%)$. 
Table-5: Study of different fetal presentation in women with uterine anomaly

\begin{tabular}{|l|l|}
\hline FETAL PRESENTATION & TOTAL CASES $(31)$ \\
\hline VERTEX PRESENTATION & $10(32.25 \%)$ \\
\hline BREECH PRESENTATION & $14(45.16 \%)$ \\
\hline TRANSEVERSE PRESENTATION & $4(12.90 \%)$ \\
\hline OBLIQUE PRESENTATION & $\mathbf{3}(9.67 \%)$ \\
\hline
\end{tabular}

In the study group most women with uterine anomaly had breech presentation $(45.16 \%)$, next common was vertex presentation $(32.25 \%)$.

\section{RESULTS}

During the study period of 2 years (20172019), 1560 Caesarean sections were performed in the Department of OBG, BGSGIMS hospital Bangalore. Out of 1560 women 31 (1.98\%) women were diagnosed as having uterine anomaly. Of the 1560 cesarean sections, 180 women underwent surgery for mal presentation and $21(11 \%)$ of them were diagnosed as having uterine anomaly (Table-1).

Women above 18 yrs who underwent cesarean section were included in the study. Out of 31 women who were diagnosed as having anomalous uterus, majority $17(54.8 \%)$ were in the age group of $25-30$ yrs and majority $20(64.51 \%)$ were primigravida (Table $2 \& 3)$.

Out of 31 anomalous uterus identified 14 $(45.16 \%)$ were bicornuate uterus, $10(32.25 \%)$ were arcuate uterus, $4(12.90 \%)$ were septate/subseptate uterus, $2(6.46 \%)$ were unicornuate uterus and 1 $(3.22 \%)$ was uterus didelphys. The most commonly observed uterine anomaly during the study period was bicornuate uterus with an incidence of $45.16 \%$, followed by arcuate uterus which was $32.25 \%$. Uterus didelphys, a rare entity, we had only 1 case during the study period (Table-4).

In the study 31 cases which were diagnosed as having anomalous uterus of which majority 24 $(77.41 \%)$ were diagnosed with breech presentation, 10 $(32.25 \%)$ had vertex presentation, $4(12.90 \%)$ had transverse presentation, $3(9.67 \%)$ had oblique presentation (Table-5).

\section{DISCUSSION}

To have an uncomplicated, normal reproductive life, a normally (anatomically and physiologically normal) functioning genital tract is required.

A number of developmental abnormalities can lead to infertility, subfertility, spontaneous abortion and preterm delivery. In females, the external genitalia, gonads, and müllerian ducts each derive from different primordia and in close association with the urinary tract and hindgut. Abnormal embryogenesis of these is thought to be multifactorial and can lead to sporadic anomalies [10].

The development of the female genital system involves complex processes of differentiation, migration, fusion and subsequent canalization of the Mullerian system. Uterine anomalies occur when these processes are interrupted [11].

The prevalence of uterine anomalies in general population is $0.1 \%$ to $10 \%$ [2-4]. Prevalence varies with the study population. In our study, prevalence of uterine anomalies in all women who underwent cesarean section is $1.98 \%$ ( 31 of 1560 cases). In another similar study conducted by Poonguzhali Liston*, Gomathy E. in Kolar prevalence of women with congenital uterine anomalies was $0.4 \%$ of the population [12]

In another study conducted by Magdy A. Mohamed et al., prevalence of uterine anomalies was $(4.75 \%)[13]$.

In another similar study conducted by Prathap $\mathrm{T}$ et al., at JSS Medical College, Mysore the incidence of uterine anomalies was found to be $13.89 \%$ [14]. In a study conducted by YY Chan, K. Jayaprakasan et al., the prevalence of all congenital uterine anomalies diagnosed in the unselected population was 5.5\% [15].

Based on the type of uterine anomalies and classification of anomalies, incidence of uterine anomalies varies in different studies. In our study we followed the most accepted method of classification of uterine anomalies - American Fertility Society as derived by Buttram and Gibbons [16].

\begin{tabular}{|l|l|}
\hline & Uterine anomaly \\
\hline 1 & Segmental or complete agenesis or hypoplasia (MRKH) \\
\hline 2 & Unicornuate uterus with or without a rudimentary horn ,subdivided as communicating and non communicating \\
\hline 3 & Didelphys uterus, Complete or partial duplication of the vagina, cervix, and uterus \\
\hline 4 & Complete or partial bicornuate uterus \\
\hline 5 & Complete or partial septate uterus \\
\hline 6 & Arcuate uterus \\
\hline 7 & DES-related \\
\hline
\end{tabular}


In our study population most common uterine anomaly identified was bicornuate uterus (45.16\%), next common was arcuate uterus $(32.25 \%)$, then septate/subseptate uterus(12.90\%), unicornuate uterus $(6.46 \%)$, didelphys(3.22\%). In another similar study conducted by Poonguzhali Liston*, Gomathy E. in Kolar common uterine anomaly identified was Bicournate uterus (43.8\%), Arcuate uterus (25\%) subseptate uterus (21.9\%), Septate uterus-2 (6.3\%), Unicournate uterus -(3.1\%) respectively [12]. In a study conducted by Magdy A. Mohamed et al., most of the anomalies were septate and sub-septate uterus (71\%) followed by bicornuate uterus $(19.4 \%)$, while the frequency of unicornuate uterus was $6.4 \%$ and uterine didelphys represented only $3.2 \%$ [13]. In another similar study conducted by Prathap $\mathrm{T}$ et al., arcuate uterus with an incidence of $46.7 \%$, followed by septate /subseptate uterus which was $20 \%$. Bicornuate uterus of $20 \%$ and unicornuate uterus-13.3\%. Uterus didelphys was not found [14].

In the study group incidence of uterine anomalies in women with mal presentation were 67.74 $\%$ (21of 31cases) and 32.25\% (10 of 31 cases) had vertex presentation. Like most of the studies, in our study population also common mal presentation associated with uterine anomaly was breech presentation. 14 of 31 women $(45.16 \%)$ had breech presentation, 4 women $(12.90 \%)$ had transverse lie and 3 women $(9.67 \%)$ had oblique lie. In the study conducted by Poonguzhali Liston*, Gomathy E. in Kolar 14 of 32 cases $(43.8 \%)$ had breech presentation, 16 of 32 cases $(50 \%)$ had cephalic, $(6.3 \%)$ and 2 of 32 cases had transverse lie [12]. In a study conducted by Prathap $\mathrm{T}$ et al., 12 out of $15(80 \%)$ had breech presentation and the rest $3(20 \%)$ had transverse lie [14].

The aim of the study was to know the prevalence of uterine anomalies during cesarean section and to know the incidence of uterine anomalies in mal presentations, hence the study was specific. Limitation of the study was the small size of the study group.

\section{CONCLUSION}

Prevalence of uterine anomalies in general population is unclear as not all women with anomalous uterus are symptomatic or will have bad obstetric history. Many women with anomalous uterus will be diagnosed incidentally during cesarean section. It is important to explore the uterus during cesarean section and diagnose uterine anomalies. Complications like recurrent miscarriages, placenta previa, placenta increta, preterm labor are associated with uterine anomalies. Proper examination of uterus during cesarean section and identifying uterine anomaly will help us to identify at risk women .In future pregnancies the women will know the probable complications and the treating obstetrician will be prepared to tackle the complications so that the Patient will have safe delivery.
Uterine anomalies do have adverse pregnancy outcome or women can have gynecological problems. Large case control studies including general population is required to know the prevalence of uterine anomalies in general population. Prenatal screening for anomalous uterus helps in early diagnosis and to prevent adverse obstetrical outcomes.

\section{REFERENCES}

1. Moore KL, Persaud TVN, Torchia MG. The Urogenital System. In Before We Are Born: Essentials of Embryology and Birth Defects. (7th edn). Saunders/Elsevier: Philadelphia, PA, 2008; 162-189.

2. Braun P, Grau FV, Pons RM, Enguix DP. Is hysterosalpingography able to diagnose all uterine malformations correctly? A retrospective study. Eur J Radiol, 2005; 53: 274-279.

3. Rackow BW, Arici A. Reproductive performance of women with müllerian anomalies. Curr Opin Obstet Gynecol, 2007; 19: 229-237.

4. Woelfer B, Salim R, Banerjee S, Elson J, Regan L. Reproductive outcomes in women with congenital uterine anomalies detected by three-dimensional ultrasound screening. Obstet Gynecol, 2001; 98:1099-1103.

5. Lawrence S Amesse, MD, PhD, MMM; Chief Editor: Richard Scott Lucidi, MD, FACOG Mullerian Duct Anomalies Updated: Apr 02, 2018.

6. Society TA. The American Fertility Society classifications of adnexal adhesions, distal tubal occlusion, tubal occlusion secondary to tubal ligation, tubal pregnancies, Müllerian anomalies and intrauterine adhesions. Fertility and sterility. 1988 Jun 1;49(6):944-55.

7. Nahum GG. Uterine anomalies. How common are they, and what their distribution among subtypes J. Reprod is. Med. 1998; 43, 877-887.

8. Grimbizis, GF, Camus, M, Tarlatzis, BC, Bontis, JN, Devroey P. Clinical implications of uterine malformations and hysteroscopic treatment results. Hum. Reprod. Update. 2001; 7, 161-174.

9. Tepper NK, Zapata LB, Jamieson DJ, Curtis KM. Use of intrauterine devices in women with uterine anatomic abnormalities. International Journal of Gynecology \& Obstetrics. 2010 Apr 1;109(1):524.

10. Williams Obstetrics, 24th Edition CHAPTER 3. Congenital Genitourinary Abnormalities, 24th Edition CHAPTER 3.

11. Chan YY, Jayaprakasan K, Tan A. Reproductive uterine anomalies: a systematic review. Ultrasound in Obstetrics \& Gynecology, 2011; 38(4):371-382

12. Poonguzhali L. Gomathy Department of Obstetrics and Gynecology, SDUAHER, Tamaka, Kolar, Karnataka, India Obstetrical outcome in women with congenital uterine anomalies. 
13. Mohamed MA, AbdelRahman MY. Frequency and types of uterine anomalies during caesarean section. Journal of Obstetrics and Gynaecology. 2019 Feb 17;39(2):147-50.

14. Prathap T, Wali NM, Prasad A. Frequency and types of uterine anomalies during caesarean section for abnormal presentation. J Evid Based Med Healthc. 2020; 7(29):1395-1398.
15. Chan YY, Jayaprakasan K, Zamora J, Thornton JG, Raine-Fenning N, Coomarasamy A. The prevalence of congenital uterine anomalies in unselected and high-risk populations: a systematic review. Human reproduction update. 2011 Nov $1 ; 17(6): 761-71$.

16. Buttram VC Jr, Gibbons WE. Müllerian anomalies: a proposed classification. (An analysis of 144 cases). Fertil Steril. 1979 Jul; 32(1):40-6. 